\title{
PROVOKED DRUG ABUSE IN PUNJAB (NARCOTICS AND OTC DRUGS CAUSING DRUG DEPENDENCE IN PUNJAB).
}

\author{
Pinky ${ }^{1}$ \\ ${ }^{1}$ Department of Pharmacology, CT Institute of Pharmaceutical Sciences, Shahpur, Jalandhar, \\ Punjab, India. \\ Mob no: 9592588138, 8054256893, E-mail: pinky252539@gmail.com.
}

The spiritual state of India, Punjab is facing a major problem of drug abuse these days. The upcoming generation is being immersed in narcotics and OTC drugs. The youth is destroying their life by drug use, HIV, Hepatitis like diseases are flourishing among generations. About more than half Punjab is drowning in drugs. Families are destroyed by drug abusers to fullfill their drug needs. Various reasons such as peer pressure, false pride, domestic circumstances and many more are responsible to make person addicted to drugs. OTC drugs are being abused as they are less expensive and easily available. Rural areas are more prone to drugs due to lack of awareness. Captain Amrinder Singh (Chief Minister of Punjab) have launched OOAT scheme to treat drug addicts, so that may become able to live drug free life. The government in collaboration with non- government organisations are taking major and strict actions against drug abuser in order to eliminate drugs from sacred state and make Punjab drug free state.

Keywords: Drug addicts, Drug abuse, OTC drugs, Narcotics, Punjab.

Abbrevations: OOAT- Outpatient Opioid Assisted Treatment

PGIMER- Postgraduate Institute of Medical Education and Research, DDAP- Drug Deaddiction Programme, DAPO- Drug Abuse Prevention Officers, HIV- Human Immuno Virus, NDPS- Narcotic Drugs and Psychotropic Substances, MoSJE- Ministry of Social Justice and Empowerment

\section{INTRODUCTION:}

In India, Punjab was known as 'Sone Di Chiri' which means 'Gold Bird', because only diet crops were grown in Punjab. It was the "Wheat basket of India". Since advancement in living style of people, introduction of selfish political system, habit of false pride, unemployment, peer pressure, high status, entertainment, domestic circumstances, disturbance in relations have pushed people of Punjab towards drugs. There is no major drug which is actually produced in Punjab. Most of the drugs come from other states through border in order to reach the major portions of India. The problem of drug dependence is becoming worst day by day in this modern scenario. Moreover, HIV and hepatitis like diseases are growing day by day by the use of contaminated syringes. Drug abuse, drug addiction, drug tolerance and drug dependence are commonly related. In developing countries like India, mostly the rural areas are influenced by use of drug. PGIMER Chandigarh entitled by "Epidemiology of Substance Abuse and Dependence in the state of Punjab (India). This survey shows some of its highlights as follow

1. 6\% are aged 11-60 yrs residing in Punjab have been dependent on any substance in their lifetime. 
2. Two million are alcohol dependent, 1.6 Million are tobacco dependent, 1 in 120 of the source population is currently dependent on opioid and estimated number of dependent persons is 0.17 million.[1]

On 23th March, 2018, the death anniversary of Shaheed Bhagat Singh, Respected Amrinder Singh (Chief Minister of Punjab) launched a Programme namely "Outpatient Opioid Assisted Treatment"under the guidance of Drug Abuse Prevention Officers (DAPO) to eradicate the problem of drug abuse and dependence.

\section{TYPES OF DRUGS AVAILABLE IN PUNJAB:}

There are number of drugs available in Punjab. Some of drugs have reached Punjab via border from neighbour countries. The main drugs used are written as follows:

A. ALCOHOL: known as 'SHARAB' and' $D A R U$ ' in Punjabi language.

a. Source: It is produced by the of fermentation grains, vegetables and fruits like grapes, apple, citrus fruits etc.

b. Geographical areas: Alcohol is found and prepared in almost all countries.

c. Effects of alcohol on body: At small doses, alcohol is cardioprotective but if taken in large amount may cause cardiovascular diseases like arrythmias, cardiac heart failure, increase in blood pressure and alterations in mood. It causes various complications like traumatic injuries, weakens immune systemdecreasing the presence of beneficial, bacteria, such as Lactobacillus and Bifidobacterium, and increasing that of Proteobacteria and Bacilli inside body, local mucosal inflammation, increase in serum endotoxin levels, liver injury, live cirhosis, hepatitis, increased susceptibility to infectioin, neuropyschological changes in adolencence, cognition, and sleep, reduced adult neurogenesis, increased neuroimmune gene expression. High intake of alchol may cause morbity and mortality also. [2]

B. TOBACCO: It is called TOBACCO in Punjabi language and is added in cigarettes, bidis, hukhas and gutka.

a. Source: It is obtained from the plant Nicotiana tabacum of family Solanaceae.

b. Geographical area: The top Producers of tobacco are China, India, Brazil and United States.[3].

c. Effects on body: Tobacco is used in the form of cigars, cigariolls, hookaas, cigarettes have dose dependent stimulant and depressant action on brain. E-cigarettes usually contain nicotine dissolved in a solution made up of propylene glycol and glycerine.[4] Carcinogens present in tobacco may cause gene mutations and cause cancer of oropharynx, laryngeal, oesophageal, stomach cancer, respiratory disorders and lung cancer. It also cause coronary heart disease, pulmonary ventricular disease, aortic aneurysm, chronic obstruction pulmonary disease, delayed conception. Smokers with diabetes have a higher risk of developing complications, including nephropathy, blindness, peripheral neuropathy, and amputations [5].

C. OPIUM: It is called as AFEEM OR NAGNI, KALI NAGNI in Punjab.

a. Source: It is dried latex of plant opium poppy Papaver somniferum. Morphine, codeine and heroin can be obtained from opium by further processing. 
b. Geographical regions: According to NDPS (Narcotic Drugs and Psychotropic Substances Act, 1985) licensed cultivation of opium is done in Uttar Pradesh, Rajasthan and Madhya Pradesh only.[6]

c. Effects on body: Raw opium can be taken orally, swallowed and also can be smoked. [7] It mainly effects the spinal cord and the brain functioning. The use of opium causes anxiety, enhanced mood, induces relaxation and mild sedation. It produces euphoria like stage. [8] At very large doses, it result in central nervous system and respiratory depressions. Generally people become out of their control and most of the crimes occurs. [9] Cardiogenic shock, tachycardia, pin point pupil, myocardial infraction and even high mortality rates can be seen. [10]

\section{MORPHINE:}

It is called MORPHINE or MARFEEN. It is the first alkaloid of opium.

Heroin is prepred by acetylation of morphine.

Codeine is prepared by the methylation of morphine:

a. Source: It is obtained from opium and is used as analgesics, anesthetic and sedatives in emergency cases.

b. Geographical areas: NDPS provide licence for the cultivation of morphine, heroin and codeine in Uttar Pradesh, Madhya Pradesh, and Rajasthan. [6]

c. Effects on body: Opioids may cause a reduction in conscious level and euphoria, making them drugs of abuse. They also exert effects on the respiratory system, reducing respiratory rate and lack of concious. Opioids are generally considered to preserve cardiac stability, histamine release and the associated reductions in systemic vascular resistance and blood pressure are marked with morphine. Amongst many other sideeffects, opioids can also cause constipation, nausea, vomiting, urinary retention, pruritus, muscular rigidity, miosis and dysphoria in certain individuals. Withdrawal symtoms are the worst with opoids. Morphine is frequently administered via oral or intravenous routes, although subcutaneous, transdermal, sublingual, intramuscular, epidural, intrathecal and intra-articular routes.[11] Morphine derivatives likehydromorphone, fentanyl, oxycodone and pethidine/ meperidine causes addiction on continous use. [12]

E. HEROIN: It is WHITE POWDER or BROWN SUGAR or a sticky black substance called BLACK TAR HEROIN or SMACK.

a. Source: It is the acetylated form of morphine.[6]

b. Effects on body: People administering heroin are examined by cognitive deficits similar to schizophrenia. Split mind, Hallucinations, meomory changes and unable to differentiate between right and wrong.[13]. It can be taken by insufflation, smoking, injection and orally. Collapsed veins, abscesses (swollen tissue with pus), infection of the lining and valves in the heart, constipation and stomach cramps, liver or kidney disease is observed.[14]

F. COCAINE: It is generally called COKE or CHITTA in punjabi.

a. Source: It is obtained from plant Erythroxylaceae coca.

b. Geographical area: It is legally cultivated in Argentinia, Bovilia, India and Peru. According to a report, Colombia is the major producer of cocaine.[15] 
c. Toxic Dose: Lethal doses are estimated at 0.5 to 1.3 grams per day by mouth; 0.05 to 5 grams per day by the nasal route, 0.02 grams of cocaine by the parenteral route [16]

d. Effect on body: Acute and chronic use of cocaine causes variety of noncardiac, systemic complications, various pathological effects on brain, heart, lung, kidneys, gastrointestinal tract, musculature and other organs may be involved.[17] It leads to decreased cerebral flow even in the face of a normal cardiac output. It may be the result of endothelial dysfunction, smooth muscle hypersensitivity, oxidative stress, genetic susceptibility and cause split behaviour. Smooth muscle hypersensitivity can be seen [18]. People taking high dose cocaine have increased libido.

G. POWDERED POPPY PODS: These are called as DODE or KHAS KHAS in punjabi

a. Source : It is obtained from the pods and straw brews of plant opium poppy Papaver somniferus.

b. Geographical areas: Afghanistan, Burma, Colombia, Mexico, Pakistan, Thailand and Northern India.[19]

c. Effect on body: Opium causes anxiety, enhanced mood, induce relaxation and mild sedation. It produces euphoria like stage. At very large doses, it result in central nervous system and respiratory depressions. Generally people become out of their control and most of the crimes occurs. Cardiogenic shock, tachycardia, pin point pupil, myocardial infraction and even high mortality rates can be seen. $[8,9,10]$.

H. CANNABIS: It is also called as BHANG or MARIJUANA in punjabi.

a. Source: It is obtained from the flowers and leaves of plant Cannabis sativa and C.indica.[20]

b. Geographical source: Feral cannabis and wild cannabis grows normally anywhere in form of wild weed and is found very commonly in Punjab.

c. Effect on body: It have behavioral and physiological effects .Behavioral effects include feeling of euphoria, relaxation, altered time perception, anxiety, pain senosry perception, impaired motor cordination lack of concentration and impaired learning, memory and mood changes like panic attacks occurs[ 20,21,22]. Physiological effects include rapid changes in heart rate and diastolic blood pressure, conjunctival suffusion, dry mouth and throat, increased appetite, vasodilatation and decreased respiratory rate. $[23,24,25]$.

\section{LIST OF THERAPEUTIC DRUG BEING ABUSED:}

There are number of therapeutic drugs which are legally marketed only in the presence of prescription. Some of these are banned in India till now. Patient may take fixed or increased dose of the drug with or without prescription and with or without phusician knowledge, ultimately being dependent on drug physiologically and psychologically.

a. OTC drugs: Some over the counter drugs were identified in many countries and were abused. Hence they were banned. These are: codeine-based (especially compound analgesic) medicines, cough products (particularly dextromethorphan), sedative antihistamines, decongestants and laxatives. Participants abusing these drugs reported a range of pleasurable effects, including alertness, cheerfulness and subsequent drowsiness; experienced withdrawal symptoms. [26] 
b. Sedative and hypnotics: drugs like lorazepa, chlorzepam, chlorpromazine also cause drug dependency. They cause dependency by neuroadaption of the cells of the brain to the presence of a drug. Hence these are given only in the presence of prescription. [27] Patient abusing barbiturate and benzodiazepines may require hospitalization for detoxifying the body. Withdrawal seizures are seen in patients taking barbiturate.[28]

c. Opoids and narcotic drugs: It includes morphine, heroin codeine methadone, hydrcodone bitartare, hydrmorphone, nomocodeine hybernil, dihydrocodeinone, Noxymorphine and others. These all have high therapeutic range but are being abused. Detoxification of the narcotic addicted and dependent is legal only in licensed clinics.[29]

\section{DRUG USE PROFILE IN PUNJAB:}

Demographic profile of opioid dependent individuals in Punjab:

$\checkmark$ Males: $99 \%$

$\checkmark$ Literate and educated: $89 \%$

$\checkmark$ Married: $54 \%$

$\checkmark$ Employed: $83 \%$

$\checkmark$ Half of the addicted population includes males.

Drug-use profile of Opioid Dependent individuals in Punjab:

$\checkmark$ Most common opioid drug: Heroin(53\%)

$\checkmark$ Using drugs through injecting route:33\% [30]

\section{FACTORS WHICH MAKE COMMON MAN TO BECOME DRUG ADDICTED:}

- Lack of job opportunities, unemployment

- A farming crisis caused by an over reliance on cash crop

- Easy availability of narcotic substances

- Ties between drug associations, organized criminal gangs, politicians and crook elements of the law enforecement agencies

- Experimental use

- Peer pressure and entertainment

- Showing high living status

- Stress and family crisis

- Burden of loan

- Psychiatric problems

- Loneliness [1]

\section{VARIOUS ORGANIZATIONS INVOLVED IN DRUG DE-ADDICTION:}

- Ministry of Health and Family Welfare, Government of India, initiated Drug Deaddiction Programme. (DDAP)

- Department of Revenue, Ministry of Finance, Government of India

- Department of the Narcotics Control Bureau, Government of India

- Department of Ministry of Home Affairs, Government of India.

- The Ministry of Social Justice and Empowerment (MoSJE), Government of India established "rehabilitation centers" run by nongovernmental organization [31] 


\section{GOVERNMENT APPROVED REHABLITAION CENTERS IN PUNJAB:}

Main motive of these centres is to:

- Handle different degree of drug addicts required different level of attention, treatment and counselling

- Curing addicts and bringing them back to main lifestream

- Motivate the addicts to say no to drugs. [32]

Government approved rehabilitation centres are: [33]

\begin{tabular}{|l|l|l|}
\hline Bathinda & Faridkot & Jalandhar \\
\hline Sangrur & Malout & Roopnagar \\
\hline Hoshiarpur & Tarn Taran & Mansa \\
\hline Fazilka & Kapurthala & S.A.S Nagar \\
\hline Barnala & Gurdaspur & Patti \\
\hline Amritsar & Fatehpur Sahib & \\
\hline
\end{tabular}

\section{CURRENT SENARIO IN PUNJAB:}

With the change in government various new programmes are launched in Punjab to eradicate drug addiction. In June 2019, Punjab CM has taken step to formulate three National Drug Policies on Enforcement, De-addiction and Prevention of drug abuse in country. Strict actions are taken against drug abuser. Also safety and security is ensured near border areas to avoid narco- terrorism from other countries. Anti drug campaign have been launched to eradicate drug abuse and implement antidrug strategy in country.

\section{DISCUSSION AND CONCLUSION:}

In conclusion, there is a great need to eliminate drug abuse in Punjab in order to save Punjab from drugs. Strict rules and regulations are needed to be formulated, high penalties should be charged to those who supply drugs, no drug or medication should be sold without prescription. Rehabilitation centres and various OOAT schemes should be available to treat the drug abusers so that they may live a respectful and drug free life. About more than half of Punjab's population is drug addicted including children, male and females. It has become very important to save Punjab's youth from being drown into drugs.

\section{CONFLICT OF INTEREST:}

There is no conflict of interest.

\section{ACKNOWLEDGMENT:}

The author is thankful to my family and institute to encourage to raise voice against drug abuse.

\section{REFERENCES:}

1. .Garg PD (2018) Opioid Addiction in North Indian States (Punjab). J Addict Med Ther 6(1):1038.

2. Patricia E. Molina and Steve Nelson, Binge's Drinking Effect on Body. Alcohol Reserch- Current reviews. 2017;39(1):1-11.

3. US Census Bureau-Foreign Trade Statistics, (Washington DC; 2005). 
4. Brown, J., Beard, E., Kotz, D., Michie. Real-world effectiveness of e-cigarettes when used to aid smoking cessation: A cross-sectional population study. Addiction 2014;109:1531-1540.

5. D. Ruiz, C.D.; Graff, D.W.; Yan, X.S. Nicotine delivery, tolerability and reduction of smoking urge in smokers following short-term use of one brand of electronic cigarettes. BMC Public Health 2015, 15, 991.

6. Avilable at: https://dor.gov.in/narcoticdrugspsychotropic/licensed-cultivation-opium.

7. Ray R, Kattimani S, Sharma HK. Opium Abuse and its Management: Global Scenario. World Health Organization. [Last accessed on 2017 Aug 29]. Available at: http://www.who.int/substance_abuse/activities/opium_abuse_management.pdf .

8. United States Department of Health and Human Services. How Tobacco Smoke Causes Disease: A Report of the Surgeon General; U.S. Department of Health and Human Services, USA, 2010.

9. Chicago: Opium, Encyclopædia Britannica; 01 September. 2016. [Last accessed on 2017 Aug 29]. Available from: https://www.britannica.com/science/opium .

10. Khosoosi Niaki MR, Hamid M, Farshidi F, Mohammadpour M, Salehi Omran MT. Evaluation of the role of opium addiction in acute myocardial infarction as a risk factor. Caspian J Intern Med. 2013;4:585-9.

11. Hasan pathan and John William, Basic opoid Pharmacology: an update $\mathrm{Br} \mathbf{J}$ Pain. 2012;6(1):11-16.

12. Martin WR, Fraser HF (1961). "A comparative study of physiological and subjective effects of heroin and morphine administered intravenously in postaddicts". J. Pharmacol. Exp. Ther. 133: 388-99.

13. Solowij N, Michie PT. Cannabis and cognitive dysfunction: Parallels with endophenotypes of schizophrenia? J Psychiatry Neurosci 2007; 32: 30-52.

14. Heoin Research Report. https://www.drugabuse.gov/drugs-abuse/commonly-abuseddrugs-charts\#heroin.

15. Dion, Michelle L; Russler, Catherine (2008). "Eradication Efforts, The State, Displacement And Poverty: Explaining Coca Cultivation In Colombia During Plan Colombia". Journal of Latin American Studies. 40.3: 399421. doi:10.1017/s0022216x08004380

16. International Programme on Chemical Safety; Poisons Information Monograph: Cocaine (PIM 139) (1999) Available from, as of November 14, 2011: http://www.inchem.org/pages/pims.html

17. Di Paolo, N.; Fineschi, V.; Di Paolo, M.; Wetly, C.V.; Garosi, G.; Del Vecchio, M.T.; Bianciardi, G. Kidney vascular damage and cocaine. Clin. Nephrol., 1997, 47(5), 298303.

18. Somlyo, A.P.; Somlyo, A.V. Signal transduction and regulation in smooth muscle. Nature, 1994, 372(6503), 231-236. [16] Lattanzio, F.A. Jr.; Tiangco, D.; Osgood, C.; Beebe, S.; Kerry, J.; Hargrave, B.Y. Cocaine increases intracellular calcium and reactive oxygen species, depolarizes mitochondria, and activates genes associated with heart failure and remodeling. Cardiovasc. Toxicol., 2005, 5(4), 377-390.

19. Professor Arthur C. Gibson. "The Pernicious Opium Poppy". University of California, Los Angeles. Archived from the original on October 20, 2013. Retrieved February 22, 2014. 
20. Geoffrey William Guy; Brian Anthony Whittle; Philip Robson (2004). The Medicinal Uses of Cannabis and Cannabinoids. Pharmaceutical Press. pp. 74-. ISBN 978-0-85369$517-2$.

21. Herkenham M, Lynn AB, Little MD, Johnson MR, Melvin LS, de Costa BR, et al. Cannabinoid receptor localization in brain. Proc Natl Acad Sci U S A. 1990;87:19321936.

22. 28. Gardner E, Lowinson JH. Marijuana's interaction with brain reward systems: update 1991. Pharmacol Biochem Behav. 1991;40:571-580.

23. 29. Devane WA, Hanus L, Breuer A, Pertwee RG, Stevenson LA, Griffin G, et al. Isolation and structure of a brain constituent that binds to the cannabinoid receptor. Science. 1992;258:1946-1949.

24. 31. Matsuda LA, Lolait SJ, Brownstein MJ, Young AC, Bonner TI. Structure of a cannabinoid receptor and functional expression of the cloned cDNA. Nature. 1990;346:561-564.

25. Howlett AC, Bidaut-Russell M, Devane WA, Melvin LS, Johnson MR, Herkenham M. The cannabinoid receptor: Biochemical, Anatomical and Behavioral characterization. Trends Neurosci. 1990;13:420-423.

26. Cooper J.Richard. Over-the-counter medicine abuse - a review of the literature. J Subst Use. 2013;18(2):82-107.

27. Donald R. Wesson, M.D. A Guide to Substance Abuse Services for Primary Care Clinicians', Appendix https://www.ncbi.nlm.nih.gov/books/NBK64823.

A-Pharmacotherapy

28. Center for Substance Abuse Treatment. The Role and Current Status of Patient Placement Criteria in the Treatment of Substance Use Disorders. Treatment Improvement Protocol (TIP) Series, Number 13. DHHS Pub. No. (SMA) 95-3021. Washington, DC: U.S. Government .Printing Office. 1995a.

29. O'Connor P.G, Waugh M.E, Carroll K.M., Rounsaville B.J., Diagkogiannis I.A, Schottenfeld R.S, Primary-care-based ambulatory opioid detoxification: The results of a clinical trial. J Gen Intern Med. 1995 May;10(5):255-60.

30. Punjab Opoid Dependence Survey (PODS) conducted by Ministry of Social Justice \& Empowerment, Government of India and Supported by Department of Health, Government of Punjab.

31. Dhawan A, Rao R, Ambekar A, Pusp A, Ray R. Treatment of substance use disorders through the government health facilities: Developments in the Drug De-addiction Programme of Ministry of Health and Family Welfare, Government of India. Indian J Psychiatry. 2017 Jul-Sep; 59(3): 380-384.

32. Report of the Special Group on Drugs, constituted by Government of Punjab, "Comprehensive action against Drug Abuse (CADA), Department of Home Affairs and Justice, Government of Punjab, August 2018.

33. Department of Health and Family Welfare. Information available at http://pbhealth.gov.in/de_efforts.html 